\title{
Aplicación del modelo de 2015 de Juliane House de evaluación de la calidad de una traducción a un texto literario: caso práctico
}

\author{
Montserrat Bermúdez Bausela
}

Recibido: 20 de noviembre de 2016 / Aceptado: 18 de abril de 2017

Resumen. En este artículo, nuestro objetivo es realizar una revisión de la evolución los modelos de evaluación de la calidad de una traducción presentados por Juliane House (1977, 1997 y 2015) y aplicar su último modelo a un texto literario. Nos gustaría plantear este artículo como un caso práctico que pudiera ser aplicable en el aula de traducción para, a su vez, comprobar si a través de la propia evaluación de traducciones, se pueden derivar una serie de pautas o consejos sobre aquellos factores que el traductor debe tener en cuenta a la hora de traducir un texto, además de saber a qué dificultades se enfrenta.

Palabras clave: Traducción, calidad, evaluación, equivalencia, función.

\section{Implementation of Juliane House's Revised 2015 Model of Translation Qua- lity Assessment to a Literary Text: A Test Case}

\begin{abstract}
In this article, our aim is to review House's translation quality assessment models (1977, 1997 and 2015) and apply her latest one to a literary text. We would like to present it as a test case that could be carried out in the Translation classroom and, at the same time, ponder if, through translation assessment criteria, we can derive some suggestions as to the factors that translators should pay particular attention when translating a text, as well as helping them face the main difficulties that they might encounter along the way.
\end{abstract}

Keywords: Translation, quality, assessment, equivalence, function.

Sumario. 1. Introducción. 2. Evolución de los modelos. 3. El original y las traducciones analizadas. 4. Aplicación del modelo de evaluación de 2015. 5. Conclusiones.

Cómo citar: Bermúdez Bausela, M. Aplicación del modelo de 2015 de Juliane House de evaluación de la calidad de una traducción a un texto literario: caso práctico, en Estudios de Trducción 7, 163-176. 


\section{Introducción}

Hasta ahora su modelo no ha sido el único (cf. Waddington 1999), pero sí uno de los más conocidos y, por ello, nos gustaría llevar su teoría a la práctica con la evaluación de dos traducciones de un fragmento de una obra literaria. En su primer modelo de 1977, House trabaja sobre un corpus de textos científicos, económicos, periodísticos y turísticos, con un claro componente funcional ideacional (referencial); así como textos pertenecientes a un sermón, un discurso político, una anécdota moral y un diálogo de comedia, es decir, textos que subrayan el carácter interpersonal (emotivo-expresivo) de los textos.

En nuestro caso, el texto original sobre el que vamos a trabajar es el capítulo $\mathrm{V}$ de la obra del escritor estadounidense Nathaniel Hawthorne The House of the Seven Gables, y sobre dos de sus traducciones: la correspondiente a 1945, así como la última traducción publicada, de 2014. Aplicaremos sobre estos textos el modelo de evaluación de 2015 de House. La elección de un tipo de texto literario no ha sido arbitraria, ya que aunque la propia autora hace referencia a ellos cuando habla de traducciones patentes, e incluso aplica su modelo de 1997 a un cuento (cf. House 2015: 71-84), su complejidad nos atrae especialmente en cuanto que nos resulta curioso el hecho de que se les pueda aplicar criterios en apariencia puramente objetivos y recogidos en un modelo, y nos invita a la reflexión.

\section{Evolución de los modelos}

Los tres modelos de House implican la comparación del "perfil textual" (la función) del texto origen (TO) y del texto meta (TM): la traducción es una operación textual, eso es innegable; y, como tal, requiere de un análisis textual detallado. No obstante, la traducción conlleva siempre una interacción entre dos tipos de factores: uno lingüístico y otro cultural, debido a que la traducción es una práctica social e interlingüística, $\mathrm{y}$, por ello, una forma de comunicación intercultural. Aparte de reconocer la importancia de los dos marcos culturales, el traductor ha de tomar en consideración "el contexto de situación" más inmediato (escritor, tiempo, función, receptor, etc.). House enfatiza a lo largo de sus modelos, y sobre todo en el último de 2015, que la traducción, en este sentido, implica un proceso de "recontextualización" de los textos a través del tiempo y el espacio (2015: 4).

Pero si hay un concepto que subyace a todos los demás, este es el concepto de "equivalencia", puesto que la traducción implica establecer el tipo de relación que se ha de dar entre el TO y el TM, y esto, a su vez, conlleva necesariamente hablar sobre la calidad de una traducción. Según su opinión, el concepto de equivalencia ha sido malinterpretado e incluso se le ha restado importancia, fundamentalmente por parte de las teorías funcionalistas, que han minimizado la importancia de la equivalencia y la han relegado a una forma especial de "adecuación" (Reiss \& Vermeer [1984] 2014), o incluso han abandonado este concepto por completo (Vermeer [1989] 2004). Bastaría con reconocer que la traducción nunca es "independiente", sino que es un texto "dependiente" y "derivado", y, por ello, ha de estar siempre vinculada a su original. House prefiere centrarse en identificar la equivalencia con la preservación del significado a través de dos lenguas y culturas distintas, a través de los tres aspectos de este significado: semántico, pragmático y textual. Lo más 
importante en la traducción es lograr la equivalencia a nivel pragmático por encima, si así fuera necesario, del aspecto semántico. Por ello, es relevante hablar de fuerza ilocutiva y de actos de habla (Austin 1962; Searle 1969). Llegamos, así, a una definición de traducción para la autora: "Translation is the replacement of a text in the source language by a semantically and pragmatically equivalent text in the target language. Since equivalence is the fundamental criterion of translation quality, an adequate translation text is a pragmatically and semantically equivalent one (2015: 23)".

Como primer requisito de esta equivalencia, se postula que una traducción ha de mantener una función equivalente a la de su TO, entendiendo por función "the application or use which the text has in the particular context of situation" (2015:26), con un componente ideacional (referencial o representativo) y un componente interpersonal (emotivo o expresivo). Pero, ¿cómo se puede determinar la función de un texto? Ciertamente un texto se halla inmerso en una situación única, por lo que para caracterizar su función textual, el texto ha de ser analizado intralingüística y extralingüísticamente en detalle. Además, el TM no solo ha de poseer la misma función textual, sino que además ha de conseguir plasmarla a través de los mismos factores situacionales y dimensionales que caracterizan el TO. El modelo original de House (1977) se fundamenta en el análisis de las dimensiones del usuario y del uso, adaptadas del modelo de Crystal \& Davy (1969), tanto del original como de su traducción, seguido por una comparación de la función textual de ambos y una evaluación del TM según haya habido una correspondencia o falta de esta. El modelo parte de las teorías del uso del lenguaje, teorías pragmáticas, la lingüística sistémica-funcional de Halliday, la Escuela de Praga del lenguaje, el concepto de registro, la estilística, el análisis discursivo, y, por supuesto, de la noción de equivalencia.

House restringe el análisis del TM a los errores (faltas de correspondencia entre TO y TM) que subdivide en dos tipos: errores patentes (overtly erroneous errors) y errores encubiertos (covertly erroneous errors). Los primeros son errores fundamentalmente de denotación en los que se da una falta de correspondencia de los significados denotativos del TO y el TM, además de errores del tipo: omisiones, adiciones, errores gramaticales, dudosa aceptabilidad, etc. Por su parte, los segundos son los errores que resultan de la falta de equivalencia funcional. Cuando en 1997 redefine el modelo original, House habla de traducciones patentes (overt translation) y de traducciones encubiertas (covert translation). En lo que se refiere a las traducciones patentes, como van a ser las de objeto de nuestro análisis, el TO está íntimamente vinculado a la comunidad de la lengua origen (LO) y a su cultura, además de poseer un estatus único en dicha comunidad. En el caso de este tipo de textos, que pueden ser textos vinculados con un momento histórico determinado (overt historically linked) o textos atemporales (overt timeless source texts), como es el caso de los textos literarios, cualquier coincidencia directa no es posible. Lo único a lo que podemos llegar a aspirar es a conseguir una función secundaria (a secondary level function). El TO ha de permanecer intacto, pero, al mismo tiempo, necesita ser transferido a una lengua diferente. Aquí, estaríamos entre dos polos: "preservación" y "alteración", algo harto difícil, ya que el traductor no debe realizar "ajustes" culturales; "simplemente" ha de transportar el TO de la cultura origen (CO) a la cultura meta (CM) y transferir el TO inalterado: "Overt translations are more 'straightforward' since their STs are taken unaltered, i.e. are merely transplanted into a new environment with no provisions being made for the TT 
addressee's (potentially different) norms of expectation (2015: 61)." La mayor dificultad reside en encontrar los equivalentes lingüísticos y culturales en lo que atañe a las dimensiones del usuario del lenguaje (dialecto temporal, social y geográfico del autor). En este tipo de traducciones, el traductor es visible. Por su lado, en el tipo de traducciones encubiertas (covert translation), el TM disfruta del estatus de original, como si se tratara del TO. Este tipo de textos no están específicamente "atados" a su LO ni a su CO, y tanto TO como TM tienen un propósito equivalente. Por todo ello, es importante mantener la función del TO equivalente en el TM y muchas veces, para lograrlo, es necesario aplicar un "filtro cultural". Es el propósito específico de la traducción el que va a determinar el tipo de traducción requerido (overt - covert); de ello va a depender que el TM pueda (o deba), o no, alcanzar una función equivalente a la del TO.

Uno de los conceptos centrales en los modelos de 1997 y 2015 es el análisis del registro. En este sentido, la autora sigue el análisis propuesto por Halliday (1989) en torno a las tres variables de campo, tenor y modo, a las cuales añade una cuarta: el estudio del género, y, en el modelo de 2015, el uso de corpus para objetivar el estudio empírico. El estudio del género nos va a permitir estudiar un ejemplo textual concreto y relacionarlo con el concepto más global del género textual al que pertenece y con el que comparte un objetivo o función común. El TO se analiza en profundidad, tanto en sus componentes lingüísticos como pragmáticos, que juntos forman el "contexto de situación", concepto que se desarrolla, a su vez, a través de las dimensiones situacionales. Cada una de las dimensiones contribuye a los dos componentes funcionales (ideacional e interpersonal). Al proceder de esta manera con el TO, se llega a establecer un perfil textual (su función). La correspondencia de perfil textual entre TO y su TM indica si este último es adecuado o no. Mantener dicha función textual o no en la traducción dependerá del tipo de traducción que se busca del original. En la "declaración de función" (statement of function), todo se mide en torno a los dos componentes funcionales: interpersonal e ideacional. A continuación, se procede a la comparación entre el TO y el TM a partir de una relación de mismatches (o faltas de equivalencia) que se producen en torno a los cuatro factores de análisis (campo, tenor, modo y género), tras lo cual se produce la "declaración de calidad" (statement of quality). En el caso de las traducciones patentes, el TO y el TM se han de mantener equivalentes a nivel de lenguaje/texto, de registro y de género, pero no de función (no se puede pensar en lograr una equivalencia de función, sino solamente permitir al receptor de la traducción acceder a la función del original). El análisis y la comparación del TO y del TM arrojarán luz sobre las normas de traducción que operan en un género textual concreto, para lo cual, lo deseado sería aumentar la investigación aplicándola a un mayor número de ejemplos (un corpus mayor) pertenecientes a textos de distintos géneros.

House introduce los conceptos de frame y frame shifting, así como discourse world y world shifting. La traducción implica una transferencia de textos a través del tiempo y del espacio, y cuando los textos se "mueven" (es decir, se traducen) también lo hacen hacia un nuevo "marco" y "mundo discursivo". El marco incluiría la interpretación del mensaje, mientras que la noción de mundo discursivo (Edmondson 1981) se referiría a una estructura superordinaria para poder interpretar el significado de una determinada manera. En una traducción patente, la traducción se encuentra inmersa en un nuevo marco y se trata de permitir al receptor del TM el acceso a la función que tiene el original en su propio mundo discursivo. Según expli- 
ca, se trataría de "co-activar" el marco y mundo discursivo original para que los miembros de la CM puedan acceder a la función textual del original, aunque desde la distancia. Sin embargo, la propia House reconoce que se necesitan llevar a cabo estudios empíricos de análisis contrastivo y pragmático que se centren en el estudio de las diferencias comunicativas y socioculturales del TO y del TM.

En la exposición de su último modelo de 2015, House concede una gran importancia a los estudios de pragmática contrastiva, comunicación y entendimiento intercultural para aplicar con mayor precisión y objetividad el filtro cultural en el caso de las traducciones encubiertas. El modelo de evaluación de la calidad de una traducción se vería muy beneficiado al integrar aspectos procedentes de estudios interculturales, puesto que la traducción es, en sí misma, un acto de comunicación intercultural entre miembros de grupos diferentes. Además, en el entendimiento intercultural está la base para el concepto de la "equivalencia funcional". Asimismo, concede una creciente importancia al estudio de los corpus aplicados a la investigación en el ámbito de traducción. El uso de corpus se percibe como una herramienta metodológica eficaz para detectar regularidades en la traducción, lo que permite verificar o refutar hipótesis a partir de la observación rigurosa de ejemplos textuales y, así, entender la norma que opera según el tipo de traducción. El estudio con corpus proporciona un mejor entendimiento de la traducción y del uso del lenguaje. Comprendemos cómo esto puede afectar de forma directa al género, ya que los resultados obtenidos a partir de corpus son relevantes para poder ir de un ejemplo concreto a una "generalidad". Las modificaciones realizadas por House en su modelo de 2015 respecto al de 1997 se justifican por la repetición innecesaria que se daba en el análisis de las variables de campo, tenor y modo. Estas modificaciones conciernen sobre todo a la inclusión de los procesos Hallidayanos en la variable de campo, el análisis de aspectos estrictamente léxicos y sintácticos en la variable de tenor, la nueva posición de la "participación" en la variable de tenor, la restricción de aspectos textuales en la variable de modo, así como el estudio de la categoría "conectividad" en esta última variable. Sin embargo, aparte de las diferencias, el estudio se sigue realizando en torno a tres pasos fundamentales: El primero es el análisis del TO, que englobaría el estudio de las variables campo, tenor, modo y género, a partir del cual se establece la "declaración de función" (statement of function). Como segundo paso, se lleva a cabo la comparación del TO y el TM a partir de una serie de mismatches o "faltas de correspondencia" (léxicos, sintácticos y/o textuales) en torno a las cuatro variables, tras lo cual llegamos al último punto, que es la propia conclusión: la "declaración de cualidad" (statement of quality). Procedamos a ver a través de un ejemplo concreto cómo se puede aplicar este último modelo a la práctica.

\section{El original y las traducciones analizadas}

Hemos escogido al destacado escritor estadounidense Nathaniel Hawthorne (Salem, Massachussets 1804 - Plymouth, New Hampshire 1864) y su obra The House of the Seven Gables, publicada en el año 1851, un año más tarde que su obra más conocida, The Scarlet Letter. Para este estudio, hemos trabajado con la edición de 1995 publicada por Wordsworth American Classics. El mismo autor nos informa en el prefacio de esta obra de que estamos ante un "Romance" y no ante la novela tradi- 
cional, la cual aspiraba, según palabras del autor, a lograr una fidelidad minuciosa y que representaba, en aquellos momentos, el realismo contemporáneo de Inglaterra. E1 Romance no solo le aporta la libertad de expresar su versión de la realidad, incluyendo elementos fantásticos, sino que le permite alejarse de su pasado puritano y llevarlo al plano de la imaginación para, de alguna forma, alejarse de él. En efecto, el puritanismo está muy presente en la obra de Hawthorne. Uno de los antepasados de Hawthorne, John Hathorne, fue un destacado juez en los procesos contra la brujería en Salem, en los años 1692 y 1693, en los que se ejecutaron a 20 personas. A raíz de estos juicios, una de sus víctimas en los juicios le maldijo a él y a su descendencia, una maldición que se hace eco en el destino de los Pyncheons en The House of the Seven Gables: "God hath given him blood to drink" (1995: 11). Este sentimiento de culpa le va a acompañar a lo largo de su vida y se va a ver reflejado en su obra.

La alegoría y el simbolismo juegan un papel primordial en la obra de Hawthorne. Tanto el autor como la familia Pyncheon de The House of the Seven Gables manifiestan su gran preocupación porque las manchas de sangre de sus antepasados no pueden limpiarse. Hawthorne percibía la rígida moral puritana como una represión del espíritu humano. La moral que subyace a su obra es que los pecados de una generación pasan a la siguiente. La maldición vertida por Matthew Maule al Coronel Pyncheon se proyecta sobre varias generaciones de descendientes, lo que demuestra que las consecuencias del pecado son imborrables. La enemistad entre las dos familias, los Maule y los Pyncheon, es también una crítica a la diferencia de clases (familia modesta de granjeros frente a la élite puritana que representa el poder) y a los defectos de la democracia americana en su momento, especialmente la ambición y la hipocresía. La decadencia tanto espiritual como material, otro de los temas principales de la obra, encuentra su personificación en la propia casa y el jardín, sin duda, dos de los símbolos más representativos de toda la novela. The House of the Seven Gables termina con el matrimonio entre Holgrave y Phoebe, algo que simboliza el fin de la maldición, y la redención de sus personajes.

Respecto a las versiones en lengua meta (LM) analizadas, contemplamos, por un lado, una de las primeras ediciones en español publicada en España por la editorial Molino: La casa de las siete torres, del traductor Enrique Cuenca Granch, nombre real de H.C. Granch, de 1945. Sin embargo, la primera traducción al españoli se la debemos a P. Elías y es de 1943 bajo el título de La casa de las siete torres. Trabajaremos, sin embargo, con la de 1945 por ser esta la más conocida y reeditada (sin ir más lejos, en el año 2013, por Plaza Editorial). Compararemos esta edición con la última traducción que existe en el mercado, de Miguel Ángel Pérez Pérez, de 2014, bajo el nombre de La casa de los siete tejados y publicada por Alianza editorial. Enrique Cuenca Granch (1892 - 1970) compartió rol como escritor y traductor fundamentalmente para la editorial Molino, donde fue uno de los autores principales de la «Serie popular Molino», dirigida a un público juvenil. Por su parte, Miguel Ángel Pérez Pérez es un reconocido traductor contemporáneo especializado en traducción literaria, ámbito en el que ha traducido, entre otros, a Charles Dickens, Arthur Conan Doyle o Jane Austin. 


\section{Aplicación del modelo de evaluación de 2015}

\section{A. Análisis del TO}

1. Campo (Field): En esta variable se estudia la temática del texto. El título del capítulo V, "May and November" es, en sí mismo, puro simbolismo: "May" representa el candor y la inocencia de Phoebe: la redención. "November" simboliza la decadencia espiritual de los Pyncheon en la figura de Hepzibah: la culpa y el pecado. El capítulo nos narra y describe la llegada de Phoebe a la casa y el tipo de relación que se establece entre ella y su prima mayor, Hepzibah. En él, vamos a poder apreciar, de forma recurrente, el contraste entre ambas, tanto físicamente como en su carácter.

1.1 En los medios léxicos (lexical means), observamos la abundancia de palabras con un claro valor simbólico, así como un gran detalle en la descripción. El léxico es, en su mayor parte, connotativo, y está vinculado con la descripción de Phoebe, Hepzibah, la casa y el jardín.

1.2 Los campos léxicos (lexical fields) pertenecen, fundamentalmente, al comportamiento humano y las creencias.

1.3 Los procesos Hallidayanos (Hallidayan processes) son de tres tipos:

- Material: Este tipo de vocabulario de tipo más "físico" lo vemos, principalmente, en aquellos casos en los que el autor nos narra lo que está aconteciendo: "Hastening down the creaking and carpetless staircase, she found her way into the garden, gathered some of the most perfect of the roses, and brought them to her chamber".

- Mental: Este tipo de vocabulario está ligado con la percepción y los sentidos: "she peeped out of the window and saw a rose-bush in the garden"; "she had observed several other species of flowers"; "one feels so very kindly towards him!", "Did you never hear [...] of Clifford Pyncheon?".

- Relacional: Este tipo de vocabulario expresa la posesión, la equivalencia y los atributos: "There were curtains to Phoebe's bed", "of a stuff which had been rich and even magnificent"; "making a night in that one corner, while elsewhere it was beginning to be day".

2. Tenor (Tenor): En esta variable, House se centra en el estudio de los distintos dialectos que caracterizan al autor, en la relación que se establece entre el autor y sus personajes, los personajes entre sí, así como la relación del papel social entre el autor y el receptor. Otros aspectos que se tratan son el estilo del texto y la participación.

2.1 Origen temporal, social y geográfico del autor (Author's temporal, social and geographical provenance): Estamos ante un dialecto geográfico de inglés americano no particularmente marcado (Standard American English). Respecto al dialecto social, enseguida se puede dar uno cuenta de que Hawthorne pertenece a una clase social culta y educada, por lo cuidado y exquisito de su prosa y descripción. Económicamente, los Hawthorne pertenecían a una clase social media que fue ascendiendo sobre todo a partir de la publicación de The Scarlet Letter y The House of the Seven Gables. En cuanto al dialecto temporal, es una obra publicada en 1851 y sí está marcada temporalmente por algunos medios léxicos como es el uso de ciertas palabras tales como: betwixt, stuff, chamber, festoons, maiden, etc.

2.2 Actitud personal del autor emocional e intelectual (Author's personal emotional and intellectual stance): Hawthorne está totalmente involucrado emocional e 
intelectualmente, algo que se aprecia en la forma en la que se implica en la forma de presentar a los personajes y las digresiones que realiza, algo que veremos también reflejado y sobre lo que volveremos a incidir posteriormente.

2.3 Relación del papel social (Social role relationship):

a) Autor-lector (Author-reader): Nos encontramos ante un autor omnisciente que acostumbra a dirigirse al receptor casi como si estuviera "dentro" de la obra. Hawthorne le hace partícipe, bien porque le menciona directamente, bien a través de sus comentarios personales: "These words, however, had not the inhospitable bluntness with which they may strike the reader..." También, el hecho de que en la narración incluya el tiempo presente, así como adverbios como now lo acercan al receptor: "They now went below stairs"; "What was precisely Phoebe's process, we find it impossible to say."

b) Autor-caracteres en la historia (Author-characters in the story): Hawthorne trata a los personajes de este capítulo con tolerancia, simpatía, ironía y hasta con sentido del humor: "'Look at my face!' -and, indeed, the contrast was very striking -'you see how pale I am!" (Hepzibah); "[Hepzibah] invited her into a room which she would probably have called her boudoir, had her education embraced any such French phrase."; "our forlorn old maid, in her rustling and rusty silks, with her deeply cherished and ridiculous consciousness of long descent."

- Medios léxicos (Hepzibah): "old maid's heart", "a dismal and lonesome old woman", "her natural inaptitude", "her habitual sluggishness",

- Medios sintácticos (Hepzibah): "as was Hepzibah of this native inapplicability, so to speak, of the Pyncheons, to any useful purpose.", "for there was neither sunshine nor household fire in one [Hepzibah] nor the other [the house]".

Todo ello contrasta con la forma en la que describe a Phoebe:

- Medios léxicos (Phoebe): "irresistible fondness", "her sweet breath and happy thoughts", "kindly and hospitable smile", "Phoebe's trim little figure", "bright, cheerful, and efficient"

- Medios sintácticos (Phoebe): "It is a kind of natural magic that enables these favoured ones to bring out the hidden capabilities around them", "You will find me a cheerful little body.", "[it] had been purified of all former evil and sorrow by her sweet breath and happy thoughts. Her dreams of the past night, being such cheerful ones, had exorcised the gloom".

Todavía es más obvio al realizar el contraste en el mismo párrafo: "the croaking and hollow tones of the old lady, and the pleasant voice of Phoebe mingling in one twisted thread of talk; and still better, to contrast their figures -so light and bloomy -so decrepit and dusky".

Hawthorne trata a estos dos personajes de forma cálida, afable, con simpatía y con empatía. Ahora bien, la actitud del autor frente a otros "personajes inanimados" de la obra cambia. Nos estamos refiriendo a la casa y al jardín, como personajes "inertes" pero, sin embargo, no tan faltos de vida (ni de muerte).

- Medios léxicos (casa): "old house", "dingy ceiling", "dark", "antique", "ponderous festoons", "grim aspect", "evil and sorrow", "dusky chamber".

- Medios sintácticos (casa): "brooded over the girl like a cloud, making a night in that one corner", "untenanted so long - except by spiders, and mice, rats, and ghosts", "It lets in the wind and rain, and the snow, too, [...]; but it never lets in the sunshine!", "but in old houses like this, you know, dead people are very apt to come back again!" 
- Medios léxicos (jardín): "rare", "blight”, "mildew”, “decay", “wilderness", "uneducated entanglement", "confusion".

- Medios sintácticos (jardín): "in soil which [...] was now unctuous with nearly two hundred years of vegetable decay", "that it was all overgrown with the desolation which watches to obliterate every trace of man's happier hours", "[flowers] growing there in a wilderness of neglect".

c) Caracteres entre ellos mismos (Characters among themselves): los personajes en este capítulo, Phoebe y Hepzibah, se tratan con respeto y cariño. "[Phoebe] Dear cousin, $[\ldots]$ I really think we may suit one another much better than you suppose."; [Hepzibah] "You are a nice girl, I see it plainly..."; "...she had naturally betaken herself to Hepzibah, with no idea of forcing herself on her cousin's protection".

Incluso Hepzibah quiere avisar a Phoebe de que la casa no es lugar para ella, ni ella misma buena compañía: "But, Phoebe, this house of mine is but a melancholy place for a young person to be in [...]. And as for myself, you see what I am -a dismal and lonesome old woman [...], whose temper, I am afraid, is none of the best..." Y se dirige a ella con apelativos cariñosos: "Well, well, child, perhaps he has!".

2.4 Actitud social (Social attitude): El estilo de Hawthorne es muy literario. Según las escalas que nos propone House y que toma de Joos (1961), creemos certero decir que se trata de un estilo "congelado" (frozen):

- Medios léxicos: El estilo visual de Hawthorne es patente en sus descripciones: "aristocratic hucksteress", "friendly remembrancers", "her rustling and rusty silks", "deeply cherished and ridiculous consciousness", "lugubriously frescoed", "great and mysterious calamity", "well-meaning and orderly young man".

- Medios sintácticos: Se caracteriza por una gran complejidad oracional. Lo vemos, por ejemplo, en esta enumeración de comparaciones: "She was very pretty, as graceful as a bird, and graceful much in the same way; as pleasant about the house as a gleam of sunshine falling on the floor through a shadow of twinkling leaves, or as a ray of firelight that dances on the wall, while evening is drawing night." $\mathrm{O}$ en digresiones del tipo: "It is a very genuine admiration, that with which persons too shy or too awkward to take a due part in the bustling world regard the real actors in life's stirring scenes; so genuine, in fact, that the former are usually fain to make it palatable to their self-love, by assuming that these active and forcible qualities are incompatible with others, which they choose to deem higher and more important."

2.5 Participación (Participation): La participación del propio autor es clave a lo largo del capítulo, como ya se ha observado, a través de numerosos ejemplos de digresiones, comentarios propios, ironías o el uso de vínculos referenciales tales como we y our, que convierten a Hawthorne en un personaje más de la historia, algo que implica, a su vez, la participación del receptor a quien van dirigidos sus comentarios.

Para concluir con el análisis del tenor, por todo lo que conocemos del autor y su obra, creemos que no nos equivocaríamos al decir que, si bien es cierto que no hay, como tal, una autoridad o una jerarquía clara entre ambos, el autor sí asume ese papel, o esa responsabilidad, que Hawthorne cree que debe transmitir a través de ese "Romance": las consecuencias de unos valores llevados al extremo y que, por ello, dejan de ser valores. En efecto, es esa moral que subyace a la obra la que nos hace creer que Hawthorne adopta un papel moralizante frente a su receptor para que no cometan los mismos errores. 
3. Modo (Mode): Esta variable contempla el estudio del medio (escrito/oral, simple/complejo), la secuenciación del texto en términos de tema-rema, y la conectividad, que consistiría en un estudio de la coherencia y la cohesión, tal y como se manifiestan en el texto.

3.1 Medio (Medium): el medio es escrito y simple: ha sido escrito y nos llega a través del género de la novela. El texto presenta una estructura lógica, muy elaborada y estudiada, que revela el tipo de premeditación propio de un estilo escrito muy cuidado.

3.2 Tema/Rema (Theme/Rheme): Los principales patrones de progresión temática que hemos podido observar son de tema constante en la parte descriptiva, repitiéndose los mismos temas: Phoebe, Hepzibah, la casa, el jardín, etc. Este patrón, indudablemente, incide en la temática tratada y en el objetivo. Son frecuentes los casos de tematización que ayudan al autor a crear el efecto dramático deseado: "Hastening down the creaking and carpetless staircase, she found her way into the garden...", "What was precisely Phoebe's process, we find it impossible to say."

3.3 Conectividad: (Connectivity coherence and cohesion): Estamos ante un texto perfectamente coherente y bien cohesionado.

- Medios textuales para afianzar esta cohesión textual: Nos gustaría destacar el uso especial del pronombre personal we y del determinante posesivo our como mecanismo del que hace uso el autor para hacer partícipe al receptor: "What was precisely Phoebe's process, we find it impossible to say"; "our forlorn old maid"; numerosos casos de repetición léxica: "festoons - festooned", "chamber - bedchamber", "ghost - ghostly"; paralelismos: “...and walked a minuet, and worked an antique tapestrystitch on her sampler"; enumeraciones: "spiders, mice and rats", "reformers, temperance lecturers, and all manner of crosslooking philanthropists, community-men, and come-outers"; comparaciones: "....and looked as if some old-fashioned personage had been sitting there all night". Al autor le gusta plantear un contraste casi constante entre el pecado y la redención, algo que se refleja en la elección del léxico a través de antónimos para asegurar el efecto dramático deseado: "dark - light", "girl - old maid", "lonesome old woman - cheerful little body", "so light and bloomy - so decrepit and dusky". Entre los campos semánticos más utilizados por Hawthorne, podemos distinguir: la religión (prayer, devotion), la decadencia (grim aspect, blight, unctuous, decay, waste, dusty, untenanted, desolation, neglect, confusion, inhospitable), la pureza (fresh, sweet, beautiful, Eden, perfect, smile, joy, happiness), o la brujería (exorcised, haunted, witchcraft).

4. Género: Hemos de clasificar esta obra dentro del género de la novela y, si nos guiamos por las palabras del propio autor, tendríamos que decir que estamos ante un Romance. Creemos que en su obra subyace un propósito comunicativo moralizante e incluso de "expiación".

Conclusión de "declaración de función": La función del TO normalmente conlleva un componente funcional ideacional y otro interpersonal. En nuestro caso, la parte ideacional es menos importante: en efecto, nos narra y describe una situación y una historia, pero esto no es lo fundamental. El componente primario es el interpersonal, el cual viene marcado en todas las dimensiones: campo, tenor, modo y género. Son los elementos interpersonales los que más abundan y los que nos permiten encuadrar este fragmento dentro de una categoría interpersonal y de ficción, puesto que pertenece al género literario de la novela, caracterizado por un estilo narrativo y minuciosamente descriptivo. 


\section{B. Comparación del TO y el TM}

La comparación se hace a partir de "faltas de correspondencia" (mismatches), que pueden ser de tipo léxico, sintáctico y/o textual, en cada uno de los cuatro puntos. Hemos seleccionado este número limitado de ejemplos que plasman la tónica general del capítulo:

\begin{tabular}{|c|c|c|}
\hline Original & $\begin{array}{c}\text { Traducción de H.C. Granch } \\
\text { (1945) }\end{array}$ & $\begin{array}{c}\text { Traducción de Miguel Pérez } \\
\text { (2014) }\end{array}$ \\
\hline $\begin{array}{l}\text {...and ponderous festoons... } \\
\text { [Campo. Carga semántica] }\end{array}$ & ...con festones... & ...con pesados festones,.. \\
\hline $\begin{array}{l}\text { Nothing, indeed, was absolutely } \\
\text { plain to her,... } \\
\text { [Campo. Carga semántica] }\end{array}$ & $\begin{array}{l}\text { Una cosa se le aparecía con } \\
\text { claridad,... }\end{array}$ & $\begin{array}{l}\text { De hecho, no tenía nada claro en } \\
\text { esos instantes,... }\end{array}$ \\
\hline $\begin{array}{l}\text { A large portion of them, as the girl } \\
\text { afterwards discovered, had blight or } \\
\text { mildew at their hearts; [Campo. } \\
\text { Simbolismo] }\end{array}$ & $\begin{array}{l}\text { Muchas de ellas, según descubrió } \\
\text { luego, albergaban pulgones en su } \\
\text { corazón, }\end{array}$ & $\begin{array}{l}\text { Gran parte de ellas, como } \\
\text { descubriría la joven más tarde, } \\
\text { estaban comidas por el añublo o el } \\
\text { moho, }\end{array}$ \\
\hline $\begin{array}{l}\text { The truth was, nevertheless, that it } \\
\text { had been planted by Alice Pyncheon } \\
\text {-she was Phoebe's great-great- } \\
\text { grand-aunt -in soil which, reckoning } \\
\text { only its cultivation as a garden plot, } \\
\text { was now unctuous with nearly two } \\
\text { hundred years of vegetable decay. } \\
\text { [Campo. Simbolismo] }\end{array}$ & $\begin{array}{l}\text { Lo plantó Alicia Pyncheon, hermana } \\
\text { de la bisabuela de Phoebe, en un } \\
\text { mantillo que doscientos años de } \\
\text { restos vegetales habían fertilizado. }\end{array}$ & $\begin{array}{l}\text { Lo cierto era, sin embargo, que lo } \\
\text { había plantado Alice Pyncheon, la } \\
\text { tataratía abuela de Phoebe, en una } \\
\text { tierra que, aunque en un principio se } \\
\text { había considerado apta para el } \\
\text { cultivo de un jardín, ahora estaba } \\
\text { plagada de casi doscientos años de } \\
\text { podredumbre vegetal. }\end{array}$ \\
\hline $\begin{array}{l}\text {... a glow of crimson light came } \\
\text { flooding through the window, and } \\
\text { bathed the dingy ceiling and paper- } \\
\text { hanging in its own hue. } \\
\text { [Tenor. Actitud social] }\end{array}$ & $\begin{array}{l}\text {... un rayo de luz carmesí tiñó el } \\
\text { deslustrado techo y el papel de la } \\
\text { pared. }\end{array}$ & $\begin{array}{l}\text {... un resplandor de luz carmesí } \\
\text { entró por la ventana e, inundando la } \\
\text { estancia, bañó de su color el } \\
\text { deslucido techo y el papel pintado. }\end{array}$ \\
\hline $\begin{array}{l}\text { Being a very tall one, and of } \\
\text { luxurious growth, it had been proppt } \\
\text { up against the side of the house, and } \\
\text { was literally covered with a rare and } \\
\text { very beautiful species of white rose. } \\
\text { [Tenor. Actitud social] }\end{array}$ & $\begin{array}{l}\text {... que se encaramaba por la pared, } \\
\text { cubriéndola con raras y hermosas } \\
\text { rosas blancas. }\end{array}$ & $\begin{array}{l}\text { Al ser muy alto y de exuberante } \\
\text { crecimiento, se apoyaba contra un } \\
\text { lado de la casa, y estaba literalmente } \\
\text { cubierto de una rara y muy hermosa } \\
\text { variedad de rosa. }\end{array}$ \\
\hline $\begin{array}{l}\text { 'Look at my face!' - and, indeed, } \\
\text { the contrast was very striking - 'you } \\
\text { see how pale I am! } \\
\text { [Tenor: Autor-lector] }\end{array}$ & $\begin{array}{l}\text { ¡Fíjate en mi rostro! - el contraste } \\
\text { era muy grande -. Ya ves cuán } \\
\text { pálida estoy. }\end{array}$ & $\begin{array}{l}\text { ¡Mira mi cara! -exclamó, y } \\
\text { ciertamente el contraste era muy } \\
\text { fuerte-. ¡Fíjate en lo pálida que } \\
\text { estoy! }\end{array}$ \\
\hline $\begin{array}{l}\text {..our forlorn old maid, in her } \\
\text { rustling and rusty silks, with her } \\
\text { deeply cherished and ridiculous } \\
\text { consciousness of long descent. } \\
\text { [Tenor: Autor - caracteres en la } \\
\text { historia] }\end{array}$ & $\begin{array}{l}\text {...ahí está Hepzibah, nuestra } \\
\text { solitaria y abandonada solterona, en } \\
\text { sus sedas ajadas y crujientes, con su } \\
\text { ridícula y amada lista de } \\
\text { antepasados. }\end{array}$ & $\begin{array}{l}\text {...no tenemos que ir más allá de } \\
\text { Hepzibah, nuestra triste solterona, } \\
\text { con sus ajadas sedas que hacían } \\
\text { frufrú, su conciencia tan enraizada y } \\
\text { ridícula de pertenecer a una } \\
\text { importante alcurnia. }\end{array}$ \\
\hline $\begin{array}{l}\text { (Phoebe:) 'Dear cousin, I cannot tell } \\
\text { how it will be,' said she. 'But I } \\
\text { really think we may suit one another } \\
\text { much better than you suppose.' } \\
\text { 'You are a nice girl, I see it plainly,' } \\
\text { continued Hepzibah"; } \\
\text { [Tenor: Caracteres entre } \\
\text { ellos mismos] }\end{array}$ & $\begin{array}{l}\text {-No lo sé, prima, pero creo que nos } \\
\text { avendremos mejor de lo que } \\
\text { supones. } \\
\text {-Eres una chica muy agradable - } \\
\text { replicó-,... }\end{array}$ & $\begin{array}{l}\text {-Querida prima, no sabría } \\
\text { explicártelo - dijo-, pero estoy } \\
\text { convencida de que nos podemos } \\
\text { llevar mucho mejor de lo que crees. } \\
\text {-Eres muy agradable, esto está claro } \\
\text { - continuó Hepzibah-, y no es nada } \\
\text { de eso lo que me hace dudar. }\end{array}$ \\
\hline $\begin{array}{l}\text { 'You are welcome, my child for the } \\
\text { present, to such a home as your } \\
\text { kinswoman can offer you.' } \\
\text { [Tenor: Caracteres entre } \\
\text { ellos mismos] }\end{array}$ & $\begin{array}{l}\text { En esta casa siempre eres bien } \\
\text { venida. }\end{array}$ & $\begin{array}{l}\text { Eres bienvenida de momento, mi } \\
\text { niña, a la casa que te puede ofrecer } \\
\text { tu familiar. }\end{array}$ \\
\hline $\begin{array}{l}\text { Hastening down the creaking and } \\
\text { carpetless staircase, she found her } \\
\text { way into the garden, gathered some } \\
\text { of the most perfect of the roses, and } \\
\text { brought them to her chamber. } \\
\text { [Modo. Tema/Rema. }\end{array}$ & $\begin{array}{l}\text { Bajó ésta la crujiente escalera, salió } \\
\text { al jardín, cogió unas rosas y se las } \\
\text { llevó a su cuarto. }\end{array}$ & $\begin{array}{l}\text { Tras bajar corriendo por la crujiente } \\
\text { escalera sin alfombra, la joven } \\
\text { encontró la salida al jardín, cogió } \\
\text { algunas de las rosas más perfectas y } \\
\text { las llevó a su habitación. }\end{array}$ \\
\hline
\end{tabular}




\section{Campo:}

La traducción de H.C. Granch de blight or mildew por "pulgones" no parece del todo acertada. La carga semántica negativa del inglés desaparece, junto con el simbolismo con el que hace referencia a ese sentimiento de culpa y a la maldición. En la traducción de Miguel Pérez, el simbolismo queda preservado a través de la traducción de "el añublo o el moho". Asimismo, con la omisión de ponderous, se pierde la connotación negativa, mientras que en la de 2014, se conserva la carga semántica.

En ocasiones, en la primera traducción se producen modulaciones en las que se ha cambiado el sentido negativo del original (nothing, indeed, was absolutely...) por la aserción de lo contrario en el TM ("una cosa se le aparecía con claridad"), algo que no ha ocurrido en la segunda traducción.

Otro ejemplo del que nos hemos querido hacer eco es la traducción de unctuous with nearly two hundred years of vegetable decay, con todo el peso negativo que representa, por "en un mantillo que doscientos años de restos vegetales habían fertilizado", una imagen positiva, todo lo contrario a lo que transmite el original; mientras que en la traducción de 2014, el simbolismo queda preservado gracias a "plagada de casi doscientos años de podredumbre vegetal".

Debido a los recurrentes casos de omisión y modulación en la primera versión, se pierde el subjetivismo con el que Hawthorne realiza su narración. El primer traductor no solo omite elementos léxicos y estructuras completas, sino que al hacerlo, borra el simbolismo que representa, por un lado, la decadencia y la culpa reflejada en el jardín, y, por otro, la fragancia y la dulzura representada por Phoebe.

2. Tenor:

- Por lo que respecta a la actitud social, en la primera traducción se dan numerosos casos de omisiones que contribuyen a la pérdida del estilo literario que caracteriza al autor, el cual es muy minucioso en sus descripciones. Mientras que en la versión más reciente podemos apreciar una traducción más literal al original que preserva el estilo literario.

- Relación autor-lector y participación: Se mantiene fiel en ambas traducciones.

- Relación autor-caracteres de la historia: En la traducción de 2014 no solo se mantiene sino que, además, cualquier posible pérdida se intenta compensar, como, por ejemplo, mediante el uso de interjecciones.

3. Modo:

- Tema/Rema: En la traducción de 2014 se preservan los casos de tematización del original. No es así en la traducción de 1945, que se caracteriza por un estilo demasiado escueto.

- Cohesión: Aunque esta se intenta preservar en ambas traducciones, la simplificación de la traducción de H.C. Granch hace que pierda fuerza cohesiva.

4. Género: Aunque, por supuesto, el género no ha variado, el tono de la traducción de H.C. Granch sí lo ha hecho. Esta traducción ha perdido el sentido moralizante y simbólico del original. Tal vez, podríamos decir que se ha realizado una traducción encubierta cuando tendría que haber sido una traducción patente.

C. Conclusión de la "declaración de calidad": El análisis del original y de la traducción ha revelado varias faltas de correspondencia entre el TO y la traducción de 1945, en especial, en lo referente a las variables de campo, tenor y modo, con un cambio sustancial en el componente funcional interpersonal de la función del texto.

Pensamos que la versión de H.C. Granch no refleja del todo, como sí lo hace la de Miguel Pérez, la constante lucha interna que le lleva a Hawthorne a enfrentarse 
con el sentimiento de culpa, decadencia, hipocresía y degeneración, sentimientos que hereda de sus ancestros puritanos y de los que hace partícipes también a sus personajes, tal y como podemos apreciar en el tenor de la versión de 2014. Creemos que la alegoría y el simbolismo se hallan mejor preservados en esta última versión, mientras que la carga moralizante se ve diluida en la primera. A partir del análisis realizado, podemos llegar a concluir que la traducción de H.C. Granch incide con mayor intensidad en el elemento ideacional, mientras que la traducción de Miguel Pérez intenta preservar la importancia del elemento interpersonal del original. También, de alguna manera, la gran diferencia existente entre las dos traducciones podría verse influida, tal vez, por las preferencias en la normativa de traducción en las distintas épocas, ya que son 69 años los que separan ambas traducciones. Asimismo, el salto temporal entre el propio original y las traducciones es relevante, al igual que lo son los diferentes receptores. Pensemos que el receptor del TO es un receptor de 1851, nada ajeno a la realidad puritana que le rodeaba y a los acontecimientos históricos tan recientes para ellos, mientras que el receptor de la traducción es un receptor de lengua española contemporáneo nuestro, del siglo XXI, que se acerca a la obra casi de forma curiosa, placentera e histórica, pero sin el efecto didáctico, moralizante e incluso de culpabilidad, que el original provocó en sus receptores originales. Al comparar la fuerza ilocutiva del original con las traducciones, percibimos que la versión de 2014 es la que más cerca está del original. En este sentido, y por todo ello, podríamos, de algún modo, decir, que la traducción de 1945 se encamina, sin serlo del todo, hacia una traducción de tipo encubierta (primando una fuerza ilocutiva de tipo referencial), mientras que la de 2014 es una traducción claramente patente (primando una fuerza ilocutiva de tipo expresivo, directivo y comisivo).

\section{Conclusiones}

En la introducción, nos planteábamos comprobar si a través de la propia evaluación de traducciones, se podían derivar una serie de consejos en torno a aquellos factores en los que el traductor debía incidir, además de ayudarnos a ser más conscientes de aquellas dificultades con las que se enfrenta. Creemos que el modelo de House, en este sentido, sí ayuda al traductor a orientar su trabajo gracias al análisis exhaustivo que realiza en torno a las cuatro variables de campo, tenor, modo y género, e invita a la reflexión sobre la mejor manera de reflejarlas en su traducción. Tal vez, si tuviéramos que incidir en una variable que supone, en particular, un arduo proceso de valoración, esta sería la variable de tenor, por la dificultad que entrañan los dialectos y el reflejo de la actitud del autor en la traducción. Asimismo, el tipo de traducción que ha de llevar a cabo vendrá condicionado por el tipo de texto y su estatus en la lengua y cultura originales, lo que le proporcionará las claves para proceder a una traducción encubierta o una traducción patente, reproduciendo la misma función que el original o, "simplemente", intentando mantener equivalentes el TO y el TM a nivel de lenguaje/texto, de registro y de género, pero no de función.

Decíamos al comienzo que la elección de un texto literario no había sido casual, ya que nos planteábamos hasta qué punto se pueden aplicar criterios objetivos recogidos en un modelo (por ello, en cierta manera, "cerrados") a un texto literario, caracterizado, quizá más que ningún otro, por su subjetividad, emotividad y expresividad. Sin embargo, la aplicación del modelo a un ejemplo concreto, nos permite 
concluir que sí nos ha resultado útil y válido para la evaluación de la traducción, puesto que, el propio análisis de las cuatro variables, es, en sí mismo, condicionante suficiente para reflexionar sobre qué factores se pueden, o no, reflejar en la traducción, sin dejar de contemplar la riqueza del componente interpersonal. Hemos podido comprobar que la "declaración de función" es un criterio razonable que nos permite comparar los perfiles textuales (las funciones) entre el original y las distintas traducciones.

Habría, en futuros trabajos y a través de la aplicación del modelo a una muestra textual más amplia, que valorar la opinión expuesta por House sobre el hecho de que en las traducciones patentes el traductor no tenga prácticamente ningún "margen de maniobra". Asimismo, creemos que la autora deja sin precisar aspectos tales como la mejor forma de "co-activar" los dos mundos o cómo proceder cuando hay dos mundos discursivos involucrados, así como la falta de una explicación más detallada de conceptos tales como de frames y discourse worlds.

\section{Referencias bibliográficas}

Austin, J., How to Do Things with Words. Oxford: Clarendon Press 1962.

Crystal, D. \& D. Davy, Investigating English Style. London: Longman 1969.

Edmondson, W., Spoken Discourse: A Model for Analysis. London: Longman 1981. Halliday, M.A.K., «Functions of language», en: Halliday, M. \& R. Hasan (eds.), Language, Context, and Text: Aspects of Language in a Social-Semiotic Perspective. Oxford: Oxford University Press 1989, 15-28.

Henry J., Hawthorne. London and New York: Macmillan 1967.

House, J., A Model for Translation Quality Assessment. Tübingen: Narr 1977.

House, J., Translation Quality Assessment: A Model Revisited. Tübingen: Narr 1997.

House, J., Translation Quality Assessment: Past and present. Routledge 2015.

Joos, M., The Five Clocks. New York: Harcourt, Brace and World 1961.

Lustig, T.J., Henry James and the Ghostly. Cambridge: Cambridge University Press 1994.

Reiss, K. \& H. Vermeer, Towards a General Theory of Translational Action. Skopos Theory Explained. Routledge [1984] 2014.

Searle, J., Speech Acts: An Essay in the Philosophy of Language. Cambridge: Cambridge University Press 1969.

Swann, C., Nathaniel Hawthorne: Tradition and Revolution. Cambridge: Cambridge University Press 2009.

Valero Garcés, C., Modelo de evaluación de obras literarias traducidas: The Scarlet Letter/La Letra Escarlata de Nathaniel Hawthorne. Peter Lang 2007.

Vermeer, H., "Skopos and Commission in Translational Action", en: Venuti, L. (ed.), The Translation Studies Reader, New York and London: Routledge, [1989] 2004, 227-38.

Waddington, C., Estudio comparativo de diferentes métodos de evaluación de traducción general (inglés-español). Universidad Pontificia Comillas 1999. 